\title{
Integration of manufacturing and pricing for downward substitution products decision-making
}

\author{
Hua $\mathrm{He}^{1,2}$ \\ Received: 14 December 2020 / Accepted: 1 March 2021 \\ (c) The Author(s) 2021
}

\begin{abstract}
With a cap-and-trade policy and green technology as inputs, we built a manufacturing ordering and pricing joint decisionmaking model for two downward substitution products to identify the conditions for optimal order quantities and prices of products under the additive demand case. Considering the case of a single period model, the conditions required for optimal manufacturing quantities and pricing were discussed, and the construction of the model was analyzed; furthermore, a study of the tactical choices between green technology inputs and manufacturing decisions was conducted, and the conditions required for green technology manufacturing input were obtained.
\end{abstract}

Keywords Stochastic demand · Cap-and-trade · Green technology investment · Downward substitution · Manufacturing and pricing strategy

\section{Introduction}

Ever since the time of the industrial revolution, which was marked by the extensive use of steam engines, fossil fuels such as coal, oil and natural gas have been used widely as energy sources. While generating tremendous power and benefits for industrial production and the lives of human beings, they inevitably caused terrible environmental problems [1]. In the Fifth Assessment Report of the IPCC-Climate Change 2014, the United Nations Intergovernmental Panel on Climate Change (IPCC) pointed out that during the 10 years between 2003 and 2012, the global average surface temperature increased by $0.78\left(0.72-0.85^{\circ} \mathrm{C}\right) \mathrm{com}$ pared with the average temperature from 1850 to 1990 . From 1901 to 2010, the global average sea level has risen by approximately $19 \mathrm{~cm}$. Since the 1950s, most of the global warming has been caused by greenhouse gas emissions, such as carbon dioxide and methane from human activities [2]. To confront the ongoing environmental degradation of the

Hua He

uestc-vip@163.com

1 School of Business Administration, Chongqing Technology and Business University, Chongqing 400067, China

2 Collaborative Innovation Center for Chongqing's Modern Trade Logistics and Supply Chain, Chongqing Technology and Business University, Chongqing 400067, China global climate, governments around the world have proactively taken actions to formulate policies and set goals. Relevant industries improve the optimization of the service efficiency, but obviously not enough, e.g., Zhao et al. [3]. At present, the major carbon emission reduction policies implemented worldwide are as follows: carbon cap, carbon tax and carbon cap-and-trade, Jin, Granda-Marulanda and Down [4]. Among them, the carbon cap-and-trade policy allows enterprises to trade carbon emissions rights freely, which makes carbon emission restrictions a kind of a "soft restriction" as well as one of the most common and effective carbon emissions reduction policies.

With the increasing pressure to reduce carbon emissions, enterprises, which are the main carbon dioxide emitters, are facing unprecedented pressure $[5,6]$. To take effective production decisions under the restrictions of carbon emission reduction policies, enterprises can obtain additional carbon emission rights by producing low-carbon products and investing in green low-carbon technology (green technology) in addition to the carbon emission rights allocated by the government $[7,8]$. At the same time, with the increasing awareness of environmental protection, lowcarbon consumption has become fashionable [9]. Research shows that consumers prefer green products and are willing to pay higher prices for lower carbon emissions in their production and consumption process, Echeverría, Moreira, Sepúlveda and Wittwer [10]. Therefore, an increasing 
number of enterprise decision makers have come to realize that investing in low-carbon green technology and reducing carbon dioxide emissions can not only satisfy the consumers' demand for a green life but also gain more competitive advantage and higher profits than competitors $[11,12]$.

\section{Literature review}

Schultz and Williamson [13] and Gong et al. [14] studied the impacts of climate change and different carbon emission reduction policies on enterprise decision-making. $\mathrm{He}$ demonstrated that companies must consider carbon emission rights to be as important resources similar to capital, human resources, products and services in terms of their direct and potential impacts. Benjaafar et al. [15] and Tang et al. [16] took the lead in introducing carbon emission factors into the supply chain system. His research found that carbon emission factors have an impact on the overall operational decision-making of supply chain enterprises. Giraud-Carrier [17] studied the operational decision-making process of manufacturing enterprises under three kinds of carbon emission reduction policy constraints and proved that any kind of a carbon emission reduction policy constraint will reduce the optimal output of a manufacturing enterprise; however, when environmental pollution is very serious, these carbon emission reduction policies will improve the overall social welfare. Ma et al. [18] studied the production decisionmaking of carbon-sensitive product manufacturers under the constraints of a carbon quota policy and analyzed the impact of the carbon quota policy and product carbon sensitivity on optimal decision-making. Ma et al. [19] extended the newsboy model and incorporated green technology input into the model. The intertemporal production decision-making of manufacturing enterprises with two production cycles under the constraint of a carbon trading policy was studied. Jian et al. [20] studied the pricing problem of competitive and cooperative products in a two-oligopoly market under the carbon cap policy constraint. Based on the extended Bertrand game model, the optimal decision-making under the two conditions of competition and cooperation was obtained. $\mathrm{He}$ and $\mathrm{Ma}$ [21] studied the production decision-making problem of two-product manufacturing enterprises under a carbon trading policy, solved and obtained the optimal production mix of manufacturing enterprises, and analyzed the impact of the carbon trading policy on the optimal decisionmaking of manufacturing enterprises.

With the rapid development of the social economy, consumer demand has become increasingly diversified and personalized. To better meet the needs of customers during the sales process, sellers need to consider demand substitution between products. Sellers often operate products with oneway substitution. These products can be divided into several grades in terms of quality or function. If there is a surplus of high-quality products and low-quality products are out of stock, sellers can meet consumers' needs by selling highquality products at low-quality prices. The management of alternative products has become a hot research topic in recent years. Most of the literature discusses price-driven substitution and inventory-driven substitution. Previously, Pentico [22] studied one-way inventory-driven substitution among products using a one-way substitution among products and obtained the optimal multiproduct production strategy by means of a dynamic programming method. Parlar [23] studied the inventory problem of two alternative products with a stochastic demand using game theory, and a Nash equilibrium solution was given. Chand et al. [24] established a part selection model with one-way substitution and used a dynamic programming algorithm to find the optimal part inventory combination. Bassok et al. [25] studied the multiproduct inventory problem of a single cycle with downward substitution and obtained the optimal multiproduct production strategy for a single cycle. Pineyro and Viera [26] studied the optimal pricing of new products and remanufactured products under non-batch production conditions. Piñeyro and Viera [27] further studied the batch problem of new products and remanufactured products by analyzing different demand flows in one-way substitutions and proposed a new algorithm to solve the model. Chen et al. [28] extended the newsboy model by incorporating product substitution into the model; in addition, the production decision-making problem of two-product manufacturing enterprises under the constraints of a carbon trading policy was studied.

There are plenty of studies on enterprise decision-making under carbon emissions trading and a one-way alternative product model, but the specifics of carbon emissions trading and of green technology investments in low-carbon products that are replacing high-carbon products is worth discussing. This paper combines one-way substitution of low-carbon products and high-carbon products with carbon emissions trading and incorporates green technology investments into the model to explore the optimal production and pricing strategy of one-way substitution of two products while analyzing green technology investments under the carbon quota and trading policy. The paper models enterprise production decision-making, considering one-way substitution and green technology as inputs under the constraints of a carbon quota and a trading policy. Generally, this is the direction in which enterprise production and sales are developing. Therefore, this paper intends to model and analyze this aspect. 


\section{Basic assumptions and parameters}

The assumption is that there is a manufacturer that faces a stochastic demand and two consumer groups in the market. Let us take the light bulb market as an example, manufacturing enterprises produce two kinds of products, energy-saving low-carbon light bulbs and ordinary light bulbs, to meet the needs of different consumers. An energy-saving low-carbon light bulb is a kind of a green product that consumes less energy and is environmentally friendly in its production process and use. Although the cost is high, the price as well as the profit is also high. In contrast, an ordinary electric light bulb is a common product that consumes more energy is not environmentally friendly, and has a low cost, low price and a low profit. At the same time, assuming that green products, but not common products, are treated by a carbon emission purification process through a green technology input, the demand is stochastic. The different advances in technology necessitate that green products have higher prices than common products. When a common product 2 is out of stock and a green product 1 is in surplus, the seller will lower the price of the green product 1 to meet the demand for the common product 2 . This is a common phenomenon in society.

On the other hand, in the context of a low-carbon economy, under the condition where there are three sources of carbon emission rights, namely, government quotas, carbon emissions trading and carbon emissions purification, as well as a single-cycle and single-emission production, the following assumptions are made:

1. Carbon emission rights are freely traded, and the market supply of carbon emission rights is adequate within a certain range.

2. The carbon emission per unit product will be a certain amount when the technology level is determined.

3. Carbon emissions of product 1 are purified by green technology $T$, and emission rights are saved. The cost of purification $c(T)$ increases with the increase of purification level $T$, which is consistent with reality.

The main parameter symbols used in this paper are as follows:

$p_{1}, p_{2}$ are the prices of green product 1 and common product 2 as determined by the market and enterprises, respectively.

$c_{1}, c_{2}$ are the unit production costs of green product 1 and common product 2 , respectively.

$h_{1}, h_{2}$ are the unit inventory costs of green product 1 and common product 2 , respectively.

$s_{1}, s_{2}$ are the unit out-of-stock costs of green product 1 and common product 2 , respectively. $q_{1}, q_{2}$ are the production quantities of green product 1 and common product 2 , respectively. The following are the decision variables:

$C E\left(q_{1}\right), C E\left(q_{2}\right)$ are the actual amounts of carbon emissions produced by green products 1 and common products 2 , respectively. They are the functions of the output with generality. Since the amount of carbon emissions per unit output is $e_{1}$ and $e_{2}$, we obtain $C E\left(q_{1}\right)=e_{1} q_{1}, C E\left(q_{2}\right)=e_{2} q_{2}$.

$c_{m 1}, c_{m 2}$ are the transaction prices of carbon emission permits per unit in the green product market of green product 1 and common product 2 , respectively.

$C E_{m 1}, C E_{m 2}$ are the carbon emission permits obtained through market transactions for green products 1 and common products 2 , respectively. When $C E_{m i}>0$, the permit is purchased, or it is sold.

$p_{1}\left(q_{1}\right), p_{2}\left(q_{2}\right)$ are the market prices of green product 1 and common product 2 , respectively, and they are determined by the output. These are the formulas for the linear inverse demand function: $p_{1}\left(q_{1}\right)=k-a q_{1}, p_{2}\left(q_{2}\right)=k-a q_{2}$.

$T$ is the input level of green technology, and $0 \leq T<1$.

$C E p_{1}$ is the production of carbon emissions from the purified treatment of green product $1 ; 0 \leq C E p_{1} \leq C E\left(q_{1}\right)$.

$C E s_{1}$ is the net emission permit obtained by the purification treatment for the production of green product 1 ; $C E s_{1}=T e_{1} q_{1}$.

\section{Model construction}

It is assumed that the price of common product $2 p_{2}$ is determined by the market and that the price of green product 1 $p_{1}$ is determined by the enterprise. Since the two products belong to the same product category, the price of the green product will affect not only its own demand but also the demand of the common product, as shown in Fig. 1.

This study assumes that the demand function of green products is

$D_{1}=d_{1}\left(p_{1}, \varepsilon_{1}\right),\left(\frac{\partial D_{1}}{\partial p_{1}}<0\right)$

$D_{2}=d_{2}\left(p_{2}, \varepsilon_{2}\right),\left(\frac{\partial D_{2}}{\partial p_{2}}>0\right)$

In the formula, $\varepsilon_{1}$ and $\varepsilon_{2}$ are the random variables on intervals $\left[A_{1}, B_{1}\right],\left[A_{2}, B_{2}\right]$, respectively.

Assume that $F_{1}(\cdot), f_{1}(\cdot), F_{2}(\cdot)$, and $f_{2}(\cdot)$ are the probability distribution function and the density function of two random variables, respectively. Since the common products are facing a competitive market, when the demand of the low-end market is not satisfied, the demand will flow to the competitors; therefore, as long as the green products are in stock, the producers will use the green products to meet the

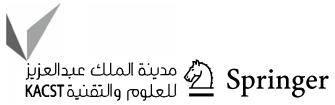


Fig. 1 Model describes

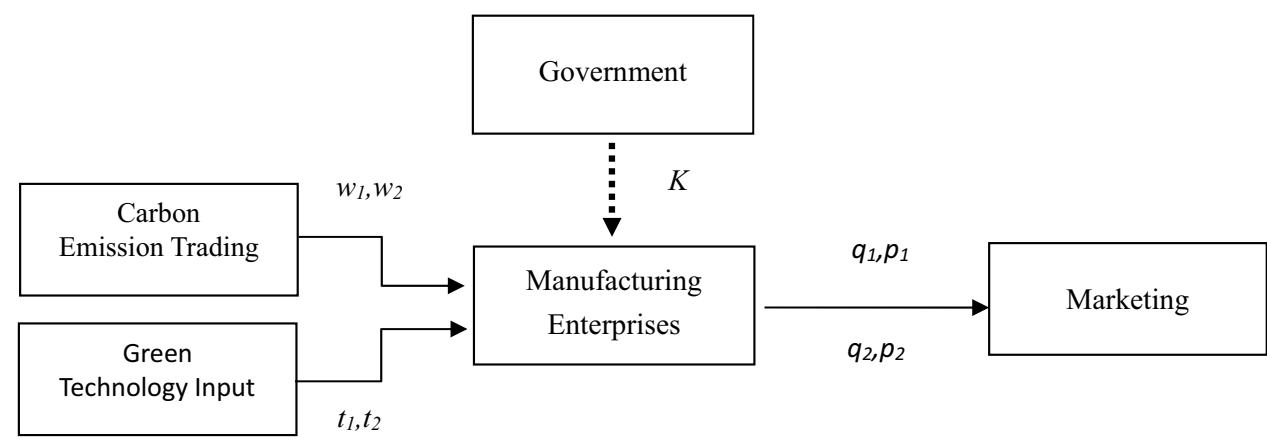

market demand when the common products are out of stock. Therefore, the manufacturer's decision is how to determine the order quantities $q_{1}$ and $q_{2}$ of green products and common products, respectively, and the price of green products $p_{1}$, under the condition of one-way substitution and the price factors, to achieve the optimal total expected profit for the enterprise.

Assume that the fixed production cost is 0 (or that it can be set as an arbitrary constant without affecting the results of the model; in this case, the calculation is simply set to 0 ), the unmet demand will be lost at the end of the cycle, the value of the surplus product will be 0 (the model can be easily extended to the case where the residual value is not zero) and that $[x]^{+}$means $\max \{0, x\}$, the profit function of the manufacturer can be expressed as follows.

At the same time, according to the hypothesis, there are three channels for the producers' carbon emission permits: government quotas $C E g_{1}, C E g_{2}$,carbon savings $T e_{1} q_{1}$ achieved by the introduction of green technology to produce green product 1 , and purchasing portions $C E m_{1}$ and $C E m_{2}$ from the carbon emission rights market. Ultimately, the emissions will not exceed the authorized load. Namely,

$$
\begin{aligned}
& C E\left(q_{1}\right) \leq C E g_{1}+T e_{1} q_{1}+C E m_{1} . \\
& C E\left(q_{2}\right) \leq C E g_{2}+C E m_{2} .
\end{aligned}
$$

In the case of a single cycle, once the emission rights reach a surplus, the producer will place them on the trading market for sale. Thus, the above inequalities can be converted into:

$C E\left(q_{1}\right)=C E g_{1}+T e_{1} q_{1}+C E m_{1}$.

$C E\left(q_{2}\right)=C E g_{2}+C E m_{2}$.

As a result, the emission rights that the producers bought on the market are $C E m_{1}$ and $C E m_{2}$ (if these values are negative, this means "sell").

$C E m_{1}=C E\left(q_{1}\right)-C E g_{1}-T e_{1} q_{1}$.

$C E m_{2}=C E\left(q_{2}\right)-C E g_{2}$.

The profit function of the manufacturer can then be expressed as follows:

$\prod\left(q_{1}, q_{2}, p_{1}\right)=\left\{\begin{array}{l}p_{1} D_{1}\left(p_{1}, \varepsilon_{1}\right)-c_{1} q_{1}-h_{1}\left[q_{1}-D_{1}\left(p_{1}, \varepsilon_{1}\right)\right]+p_{2} D_{2}\left(p_{1}, \varepsilon_{2}\right)-c_{2} q_{2} \\ -h_{2}\left[q_{2}-D_{2}\left(p_{1}, \varepsilon_{2}\right)\right]-c_{m 1} C E_{m 1}-c(T)-c_{m 2} C E_{m 2} \\ D_{1}\left(p_{1}, \varepsilon_{1}\right) \leq q_{1}, D_{2}\left(p_{2}, \varepsilon_{2}\right) \leq q_{2} \\ p_{1} q_{1}-c_{1} q_{1}-s_{1}\left[D_{1}\left(p_{1}, \varepsilon_{1}\right)-q_{1}\right]+p_{2} D_{2}\left(p_{1}, \varepsilon_{2}\right)-c_{2} q_{2} \\ -h_{2}\left[q_{2}-D_{2}\left(p_{1}, \varepsilon_{1}\right)\right]-c_{m 1} C E_{m 1}-c(T)-c_{m 2} C E_{m 2} \\ D_{1}\left(p_{1}, \varepsilon_{1}\right)>q_{1}, D_{2}\left(p_{2}, \varepsilon_{2}\right) \leq q_{2} \\ p_{1} D_{1}\left(p_{1}, \varepsilon_{1}\right)-c_{1} q_{1}-h_{1}\left[q_{1}-D_{1}\left(p_{1}, \varepsilon_{1}\right)-D_{2}\left(p_{1}, \varepsilon_{2}\right)+q_{2}\right]^{+} \\ +p_{2}\left\{q_{2}+\min \left\{\left[q_{1}-D_{1}\left(p_{1}, \varepsilon_{1}\right)\right],\left[D_{2}\left(p_{1}, \varepsilon_{2}\right)-q_{2}\right]\right\}\right\}-c_{2} q_{2} \\ -s_{2}\left[D_{2}\left(p_{1}, \varepsilon_{2}\right)-q_{2}-q_{1}+D_{1}\left(p_{1}, \varepsilon_{1}\right)\right]^{+}-c_{m 1} C E_{m 1}-c(T)-c_{m 2} C E_{m 2} \\ D_{1}\left(p_{1}, \varepsilon_{1}\right) \leq q_{1}, D_{2}\left(p_{2}, \varepsilon_{2}\right)>q_{2} \\ p_{1} q_{1}-c_{1} q_{1}-s_{1}\left[D_{1}\left(p_{1}, \varepsilon_{1}\right)-q_{1}\right]+p_{2} q_{2}-c_{2} q_{2}-s_{2}\left[D_{2}\left(p_{1}, \varepsilon_{2}\right)-q_{2}\right] \\ -c_{m 1} C E_{m 1}-c(T)-c_{m 2} C E_{m 2} \\ D_{1}\left(p_{1}, \varepsilon_{1}\right)>q_{1}, D_{2}\left(p_{2}, \varepsilon_{2}\right)>q_{2}\end{array}\right.$. 
The above profit function shows the following:

1. When both of the demands of the two products are smaller than their outputs, the profit of the enterprise equals the income of the two products minus the sum of the ordering cost and the inventory cost;

2. When the green products are out of stock and the common products are in surplus, the common products cannot replace the green products; thus, the total profit of the enterprise equals the total income of the two products minus the sum of the total production cost, the shortage cost of the green products and the inventory cost of the common products.

3. When the green products are in surplus and the common products are out of stock, the producer will use the surplus green products to meet the demand of the common products. The profit of the enterprise equals the total income of the two products minus the sum of the total order cost and the inventory cost of the surplus green products, while replacing the common products or the shortage cost of the green products by green products.

4. When the demand for both products is greater than their respective outputs, the profit of the enterprise equals the total income of the two products minus the sum of the total order cost and the shortage cost.
To facilitate the analysis of the model, the form of the demand function is set as an additive form: $D(p, \varepsilon)=d(p)+\varepsilon$. The profit function is simplified as $z_{1}=q_{1}-d_{1}\left(p_{1}\right)$ and $z_{2}=q_{2}-d_{2}\left(p_{2}\right)$ to represent the level of the risk-free inventory, Thowsen [29], selected by

By substituting Formula (5) and Formula (6) into Formula (7), the following results can be obtained:

$$
\prod\left(q_{1}, q_{2}, p_{1}\right)=\left\{\begin{array}{l}
p_{1} D_{1}\left(p_{1}, \varepsilon_{1}\right)-c_{1} q_{1}-h_{1}\left[q_{1}-D_{1}\left(p_{1}, \varepsilon_{1}\right)\right]+p_{2} D_{2}\left(p_{1}, \varepsilon_{2}\right)-c_{2} q_{2}-h_{2}\left[q_{2}-D_{2}\left(p_{1}, \varepsilon_{2}\right)\right] \\
-c_{m 1} C E\left(q_{1}\right)+c_{m 1} C E g_{1}+\left[c_{m 1} T e_{1} q_{1}-c(T)\right]-c_{m 2} C E\left(q_{2}\right)+c_{m 2} C E g_{2} \\
D_{1}\left(p_{1}, \varepsilon_{1}\right) \leq q_{1}, D_{2}\left(p_{2}, \varepsilon_{2}\right) \leq q_{2} \\
p_{1} q_{1}-c_{1} q_{1}-s_{1}\left[D_{1}\left(p_{1}, \varepsilon_{1}\right)-q_{1}\right]+p_{2} D_{2}\left(p_{1}, \varepsilon_{2}\right)-c_{2} q_{2}-h_{2}\left[q_{2}-D_{2}\left(p_{1}, \varepsilon_{1}\right)\right] \\
-c_{m 1} C E\left(q_{1}\right)+c_{m 1} C E g_{1}+\left[c_{m 1} T e_{1} q_{1}-c(T)\right]-c_{m 2} C E\left(q_{2}\right)+c_{m 2} C E g_{2} \\
D_{1}\left(p_{1}, \varepsilon_{1}\right)>q_{1}, D_{2}\left(p_{2}, \varepsilon_{2}\right) \leq q_{2} \\
p_{1} D_{1}\left(p_{1}, \varepsilon_{1}\right)-c_{1} q_{1}-h_{1}\left[q_{1}-D_{1}\left(p_{1}, \varepsilon_{1}\right)-D_{2}\left(p_{1}, \varepsilon_{2}\right)+q_{2}\right]^{+}+p_{2}\left\{q_{2}+\min \left\{\left[q_{1}-D_{1}\left(p_{1}, \varepsilon_{1}\right)\right]\right.\right. \\
\left.\left.\left[D_{2}\left(p_{1}, \varepsilon_{2}\right)-q_{2}\right]\right\}\right\}-c_{2} q_{2}-s_{2}\left[D_{2}\left(p_{1}, \varepsilon_{2}\right)-q_{2}-q_{1}+D_{1}\left(p_{1}, \varepsilon_{1}\right)\right]^{+} \\
-c_{m 1} C E\left(q_{1}\right)+c_{m 1} C E g_{1}+\left[c_{m 1} T e_{1} q_{1}-c(T)\right]-c_{m 2} C E\left(q_{2}\right)+c_{m 2} C E g_{2} \\
D_{1}\left(p_{1}, \varepsilon_{1}\right) \leq q_{1}, D_{2}\left(p_{2}, \varepsilon_{2}\right)>q_{2} \\
p_{1} q_{1}-c_{1} q_{1}-s_{1}\left[D_{1}\left(p_{1}, \varepsilon_{1}\right)-q_{1}\right]+p_{2} q_{2}-c_{2} q_{2}-s_{2}\left[D_{2}\left(p_{1}, \varepsilon_{2}\right)-q_{2}\right] \\
-c_{m 1} C E\left(q_{1}\right)+c_{m 1} C E g_{1}+\left[c_{m 1} T e_{1} q_{1}-c(T)\right]-c_{m 2} C E\left(q_{2}\right)+c_{m 2} C E g_{2} \\
D_{1}\left(p_{1}, \varepsilon_{1}\right)>q_{1}, D_{2}\left(p_{2}, \varepsilon_{2}\right)>q_{2}
\end{array}\right.
$$


the enterprises for the two types of products. The simplified enterprise profit function is expressed as follows:
The expected profit function can be rewritten as follows:

$$
\begin{aligned}
& \prod\left(q_{1}, q_{2}, p_{1}\right) \\
& =\left\{\begin{array}{l}
p_{1}\left[d_{1}\left(p_{1}\right)+\varepsilon_{1}\right]-c_{1}\left[d_{1}\left(p_{1}\right)+z_{1}\right]-h_{1}\left[z_{1}-\varepsilon_{1}\right]+p_{2}\left[d_{2}\left(p_{1}\right)+\varepsilon_{2}\right]-c_{2}\left[d_{2}\left(p_{1}\right)+z_{2}\right]-h_{2}\left[z_{2}-\varepsilon_{2}\right] \\
-c_{m 1} e_{1}\left[d_{1}\left(p_{1}\right)+z_{1}\right]+c_{m 1} C E g_{1}+\left[c_{m 1} T e_{1} q_{1}-c(T)\right]-c_{m 2} e_{2}\left[d_{2}\left(p_{1}\right)+z_{2}\right]+c_{m 2} C E g_{2} \\
\varepsilon_{1} \leq z_{1}, \varepsilon_{2} \leq z_{2} \\
p_{1}\left[d_{1}\left(p_{1}\right)+\varepsilon_{1}\right]-c_{1}\left[d_{1}\left(p_{1}\right)+\varepsilon_{1}\right]-s_{1}\left[\varepsilon_{1}-z_{1}\right]+p_{2}\left[d_{2}\left(p_{1}\right)+\varepsilon_{2}\right]-c_{2}\left[d_{2}\left(p_{1}\right)+z_{2}\right]-h_{2}\left[z_{2}-\varepsilon_{2}\right] \\
-c_{m 1} e_{1}\left[d_{1}\left(p_{1}\right)+z_{1}\right]+c_{m 1} C E g_{1}+\left[c_{m 1} T e_{1} q_{1}-c(T)\right]-c_{m 2} e_{2}\left[d_{2}\left(p_{1}\right)+z_{2}\right]+c_{m 2} C E g_{2} \\
\varepsilon_{1}>z_{1}, \varepsilon_{2} \leq z_{2} \\
p_{1}\left[d_{1}\left(p_{1}\right)+\varepsilon_{1}\right]-c_{1}\left[d_{1}\left(p_{1}\right)+z_{1}\right]-h_{1}\left[z_{1}-\varepsilon_{1}-z_{2}+\varepsilon_{2}\right]+p_{2}\left\{d_{2}\left(p_{1}\right)+\varepsilon_{2}+\min \left\{\left[z_{1}-\varepsilon_{1}\right],\left[\varepsilon_{2}-z_{2}\right]\right\}\right\} . \\
-c_{2}\left[d_{2}\left(p_{1}\right)+z_{2}\right]-s_{2}\left[\varepsilon_{2}-z_{2}-z_{1}+\varepsilon_{1}\right]-c_{m 1} e_{1}\left[d_{1}\left(p_{1}\right)+z_{1}\right]+c_{m 1} C E g_{1}+\left[c_{m 1} T e_{1} q_{1}-c(T)\right] \\
-c_{m 2} e_{2}\left[d_{2}\left(p_{1}\right)+z_{2}\right]+c_{m 2} C E g_{2} \\
\varepsilon_{1} \leq z_{1}, \varepsilon_{2}>z_{2} \\
p_{1}\left[d_{1}\left(p_{1}\right)+\varepsilon_{1}\right]-c_{1}\left[d_{1}\left(p_{1}\right)+z_{1}\right]-s_{1}\left[\varepsilon_{1}-z_{1}\right]+p_{2}\left[d_{2}\left(p_{1}\right)+\varepsilon_{2}\right]-c_{2}\left[d_{2}\left(p_{1}\right)+z_{2}\right]-s_{2}\left[\varepsilon_{2}-z_{2}\right] \\
-c_{m 1} e_{1}\left[d_{1}\left(p_{1}\right)+z_{1}\right]+c_{m 1} C E g_{1}+\left[c_{m 1} T e_{1} q_{1}-c(T)\right]-c_{m 2} e_{2}\left[d_{2}\left(p_{1}\right)+z_{2}\right]+c_{m 2} C E g_{2} \\
\varepsilon_{1}>z_{1}, \varepsilon_{2}>z_{2}
\end{array}\right.
\end{aligned}
$$

From the simplified profit function, it can be observed that the inventory will be generated when the risk-free inventory levels $z_{1}$ and $z_{2}$ chosen by the enterprise exceed the actual quantities $\varepsilon_{1}$ and $\varepsilon_{2}$ When the risk-free inventory levels $z_{1}$ and $z_{2}$ are lower than the actual quantities $\varepsilon_{1}$ and $\varepsilon_{2}$, this will lead to a shortage, so the expected profit of the enterprise can be expressed as follows:

$$
\begin{aligned}
E\left[\prod\left(z_{1}, z_{2}, p_{1}\right)\right]= & \Psi\left(p_{1}\right)-L\left(z_{1}, z_{2}, p_{1}\right) \\
& -c_{m 1} e_{1}\left[d_{1}\left(p_{1}\right)+z_{1}\right]+c_{m 1} C E g_{1} \\
+ & +\left[c_{m 1} e_{1} q_{1}-c(T)\right] .+c_{m 2} e_{2}\left[d_{2}\left(p_{1}\right)+z_{2}\right] \\
+ & +c_{m 2} C E g_{2}
\end{aligned}
$$

Among them,

$$
\begin{aligned}
& E\left[\prod\left(z_{1}, z_{2}, p_{1}\right)\right]= \\
& p_{1}\left\{\int_{A_{1}}^{z_{1}}\left[d_{1}\left(p_{1}\right)+x\right] f_{1}(x) d x+\int_{z_{1}}^{B_{1}}\left[d_{1}\left(p_{1}\right)+z_{1}\right] f_{1}(x) d x\right\}+p_{2}\left\{\int_{A_{1}}^{z_{1}} \int_{A_{2}}^{z_{1}+z_{2}-x}\left[d_{2}\left(p_{1}\right)+y\right] f_{2}(y) f_{1}(x) d y d x\right. \\
& +\left\{\int_{A_{1}}^{z_{1}} \int_{z_{1}+z_{2}-x}^{B_{2}}\left[d_{2}\left(p_{1}\right)+z_{2}+z_{1}-x\right] f_{2}(y) f_{1}(x) d y d x\right\}-s_{1} \int_{z_{1}}^{B_{1}}\left(x-z_{1}\right) f_{1}(x) d x-h_{2} \int_{A_{2}}^{z_{2}}\left(z_{2}-y\right) f_{2}(y) d y . \\
& -h_{1} \int_{z_{2}}^{B_{2}} \int_{A_{1}}^{z_{1}+z_{2}-x}\left[z_{1}-x-z_{2}-y\right] f_{1}(x) f_{2}(y) d x d y-s_{2} \int_{A_{1}}^{z_{1}} \int_{z_{1}+z_{1}-x}^{B_{2}}\left(y-z_{2}+x-z_{1}\right) f_{2}(y) f_{1}(x) d y d x \\
& -c_{1}\left[d_{1}\left(p_{1}\right)+z_{1}\right]-c_{2}\left[d_{2}\left(p_{2}\right)+z_{2}\right]-c_{m 1} e_{1}\left[d_{1}\left(p_{1}\right)+z_{1}\right]+c_{m 1} C E g_{1}+\left[c_{m 1} T e_{1} q_{1}-c(T)\right]+c_{m 2} C E g_{2}
\end{aligned}
$$

$\Lambda_{1}\left(z_{1}\right)=\int_{A_{1}}^{z_{1}}\left(z_{1}-x\right) f_{1}(x) d x, \Lambda_{2}\left(z_{2}\right)=\int_{A_{2}}^{z_{2}}\left(z_{2}-y\right) f_{2}(y) d y$. This represents the possibility that a shortage occurs when the risk-free inventory level $z_{1}, z_{2}$ chosen by the enterprise is too low.

$$
\Phi\left(z_{1}, z_{2}\right)=\int_{z_{2}}^{B_{2}} \int_{A_{1}}^{z_{1}+z_{2}-y}\left(z_{1}-x+z_{2}-y\right) f_{1}(x) f_{2}(y) d x d y .
$$

This indicates the possibility that green products will still be in stock after replacing common products.

$\Psi\left(z_{1}, z_{2}\right)=\int_{A_{1}}^{z_{1}} \int_{z_{1}+z_{2}-x}^{B_{2}}\left(x-z_{1}+y-z_{2}\right) f_{2}(y) f_{1}(x) d y d x$.This indicates the possibility that green products will be out of stock after replacing the common products.
$\Psi\left(p_{1}\right) \equiv\left(p_{1}-c_{1}\right)\left[d_{1}\left(p_{1}\right)+\mu_{1}\right]+\left(p_{2}-c_{2}\right)\left[d_{2}\left(p_{1}\right)+\mu_{2}\right]$.

$$
\begin{aligned}
& L\left(z_{1}, z_{2}, p_{1}\right) \\
& \equiv \quad\left[c_{1} \Lambda_{1}\left(z_{1}\right)+h_{1} \Phi\left(z_{1}, z_{2}\right)+\left(p_{1}+s_{1}-c_{1}\right) \Theta_{1}\left(z_{1}\right)\right] \\
& \quad+\left[\left(c_{2}+h_{2}\right) \Lambda_{2}\left(z_{2}\right)+\left(p_{2}+s_{2}\right) \Psi\left(z_{2}, z_{1}\right)-c_{2} \Theta_{2}\left(z_{2}\right)\right] .
\end{aligned}
$$

Formula (12) represents the risk-free profit function, which is a deterministic equilibrium problem, in which $\varepsilon_{1}$ and $\varepsilon_{2}$ are replaced by $\mu_{1}$ and $\mu_{2}$. Formula (13) represents the loss function. Part 1 represents the loss caused by the 
uncertainty of the green products, including the inventory loss $c_{1} \Lambda_{1}\left(z_{1}\right)+h_{1} \Phi\left(z_{1}, z_{2}\right)$ when output exceeds demand and the shortage loss $\left(p_{1}+s_{1}-c_{1}\right) \Theta_{1}\left(z_{1}\right)$ when the output is lower than the demand. Part 2 shows the loss of common products due to uncertainty, including the loss of inventory $\left(c_{2}+h_{2}\right) \Lambda_{2}\left(z_{2}\right)$ when the output exceeds the demand and the loss of shortage $\left(p_{2}+s_{2}\right) \Psi\left(z_{2}, z_{1}\right)-c_{2} \Theta_{2}\left(z_{2}\right)$ when the output is lower than the demand. Therefore, the total expected profit of the enterprise in Formula (11) can be described as the net surplus of the risk-free profit under deterministic conditions minus the expected loss due to uncertainty.

The goal of an enterprise is to maximize the total expected profits:

$\underset{z_{1}, z_{2}, p_{1}}{\operatorname{Max}} E\left[\prod\left(z_{1}, z_{2}, p_{1}\right)\right]$.

To simplify the research results, the demand function is assumed to be a linear function:

$d_{1}\left(p_{1}\right)=a-b p_{1}(a>0, b>0)$

$d_{2}\left(p_{1}\right)=a+\beta p_{1}(a>0, \beta>0)$

The First- and Second-Order Partial Derivatives of $p_{1}$ are found by pairing Formula (14) as follows:

$\frac{\partial E\left[\prod\left(z_{1}, z_{2}, p_{1}\right)\right]}{\partial p_{1}}=2 b\left(p_{0}-p_{1}\right)-\Theta\left(z_{1}\right)$.

$\frac{\partial^{2} E\left[\prod\left(z_{1}, z_{2}, p_{1}\right)\right]}{\partial p_{1}^{2}}=-2 b$.

Among them, $p_{0}=\frac{a+b c_{1}+\mu_{1}+\beta\left(p_{2}-c_{2}\right)+b c_{m 1} e_{1}-\beta c_{m 2} e_{2}}{\text {, }}$ that is, $p_{0}=\frac{a+b\left(c_{1}+c_{m 1} e_{1}\right)+\mu_{1}+\beta\left(p_{2}-2_{2}^{b}-c_{m 2} e_{2}\right)}{2 b}$.

The risk-free price representing the optimal consideration of carbon emissions and trading is obtained by maximizing the risk-free profit function $\Psi\left(p_{1}\right)$ (when considering different carbon-rights trading markets for carbon emissions).

It can be observed from Formula (16) that under the given conditions of $z_{1}$ and $z_{2}$, the expected profit function $E\left[\prod\left(z_{1}, z_{2}, p_{1}\right)\right]$ is a strictly concave function of the price. Therefore, the optimal inventory level can be redetermined by first finding out the functional relationship between the optimal price $p_{1}^{*}$ and $z_{1}, z_{2}$ through $\frac{\partial E\left[\prod\left(z_{1}, z_{2}, p_{1}\right)\right]}{\partial p_{1}}=0$ and then substituting it into Formula (14).

Conclusion 1: under the condition that the demand function is in an additive form, the optimal price is $p_{1}^{*}$, the optimal output is $q_{1}^{*}=z_{1}^{*}+d_{1}\left(p_{1}^{*}\right), q_{2}^{*}=z_{2}^{*}+d_{2}\left(p_{1}^{*}\right)$ and the optimal price and the optimal output satisfy the following conditions:

1. Under a given condition of $z_{1}$ and $z_{2}$, the optimal price $p_{1}^{*}$ is lower than the optimal risk-free price $p_{1}$ and is a function of the risk-free inventory level. The functional relationship is as follows:

$p_{1}^{*}=p_{1}\left(z_{1}\right)=p_{0}-\frac{\Theta\left(z_{1}\right)}{2 b}$.

2. When the probability density function of a random variable satisfies

$f_{1}\left(z_{1}\right)<\min \left\{2 b s_{1}\left[r_{1}\left(z_{1}\right)\right]^{2}, r_{1}\left(z_{1}\right) r_{2}\left(z_{2}\right) /\left[r_{1}\left(z_{1}\right)+r_{2}\left(z_{2}\right)\right]\right\}$.

When $\left(A_{1} \leq z_{1} \leq B_{1}, A_{2} \leq z_{2} \leq B_{2}\right)$, the expected profit function $E\left[\prod\left(z_{1}, z_{2}, p_{1}\left(z_{1}\right)\right)\right]$ is a strict concave function of $z_{1}$ and $z_{2}$, and there are optimal risk-free inventory levels $z_{1}^{*}$ and $z_{2}^{*}$.

Prove:

Conditions (1) can be obtained from Formula (15), which equals 0. $p_{1}^{*}=p_{0}-\frac{\Theta\left(z_{1}\right)}{2 b}$, since $\Theta\left(z_{1}\right)$ is nonnegative; Petruzzi and Dada [30] obtained the same result for a product.

The proof of condition 2 is omitted.

Under the condition that the conclusion is satisfied, the optimal risk-free inventory levels $z_{1}^{*}$ and $z_{2}^{*}$ can be obtained by solving the following equations:

$$
\begin{aligned}
\frac{\partial E\left[\Pi\left(z_{1}, z_{2}, p_{1}\left(z_{1}\right)\right)\right]}{\partial z_{1}}= & {\left[p_{0}-s_{1}-\frac{\Theta\left(z_{1}\right)}{2 b}\right]\left[1-F_{1}\left(z_{1}\right)\right] } \\
& +\left(p_{2}+s_{2}\right)\left\{F_{1}\left(z_{1}\right)\left[1-f_{2}\left(z_{2}+z_{1}-x\right)\right]\right. \\
& \left.-f_{1}\left(z_{1}\right) \Theta_{2}\left(z_{2}\right)\right\}-c_{1}-h_{1}\left[1-F_{2}\left(z_{2}\right)\right] \\
& F_{1}\left(z_{1}+z_{2}-y\right)=0 .
\end{aligned}
$$

Based on the optimal inventory level and actual demand, the optimal production volume can be obtained:

$q_{1}^{*}=z_{1}^{*}+d_{1}\left(p_{1}^{*}\right)$

$q_{2}^{*}=z_{2}^{*}+d_{2}\left(p_{1}^{*}\right)$

Obtain evidence.

\section{Input of green technology and selection of the production strategy for green products}

This section examines the problem of green technology input and green product production strategy selection; that is, it analyzes the relationship between $\mathrm{E}\left[\Pi\left(z_{1}, z_{2}, p_{3}\left(z_{1}\right)\right)\right]$ and $T$.

1. If $\frac{c^{\prime}(T)}{e_{1} q_{1}}<c_{m 1}$, we can obtain $\frac{\partial E\left[\Pi\left(z_{1}, z_{2}, p_{1}\right)\right]}{\partial T}>0$ from Formula (11), and $E\left[\Pi\left(z_{1}, z_{2}, p_{1}\right)\right]$ continuously increases along with $T$; that is, the investment in green technology can increase the expected profits of enterprises through the 
production of green product 1 , and so the enterprises will invest in green technology to produce green product 1 .

2. If $\frac{c^{\prime}(T)}{e_{1} q_{1}}=c_{m 1}$, we can observe $\frac{\partial E\left[\Pi\left(z_{1}, z_{2}, p_{1}\right)\right]}{\partial T}=0$ from Formula (11), which means that the investment in green technology cannot increase the expected profits of enterprises by producing green product 1 , and thus, enterprises will not invest in the green technology to produce green product 1. 3. If $\frac{c^{\prime}(T)}{e_{1} q_{1}}>c_{m 1}$, we can observe $\frac{\partial E\left[\Pi\left(z_{1}, z_{2}, p_{1}\right)\right]}{\partial T}<0$ from Formula (11); that is, a continuous decline, which means that the investment in green technology will reduce the expected profits of enterprises while producing green product 1 . Therefore, the enterprises will not invest in the green technology to produce green product 1 .

\section{Conclusion}

In recent years, under the influence of a low-carbon economy, more and more enterprises have started to produce and sell alternative diversified products. This paper studies the joint decision-making involved in the production and pricing of two products with one-way substitution under the condition of carbon trading and green technology investment with a stochastic demand. In the case of a single cycle, when the distribution function of the random variables satisfies certain conditions, there is a unique optimal output and price for enterprises that conform to an additive demand function. At the same time, the conditions required for enterprises to consider including green technology in their production are obtained. In the future, further studies on the production and price decision-making in one-way substitutions of two products should be conducted by analyzing multicycle green technology investments under the conditions of carbon quotas and trading or asymmetric information structures.

Open Access This article is licensed under a Creative Commons Attribution 4.0 International License, which permits use, sharing, adaptation, distribution and reproduction in any medium or format, as long as you give appropriate credit to the original author(s) and the source, provide a link to the Creative Commons licence, and indicate if changes were made. The images or other third party material in this article are included in the article's Creative Commons licence, unless indicated otherwise in a credit line to the material. If material is not included in the article's Creative Commons licence and your intended use is not permitted by statutory regulation or exceeds the permitted use, you will need to obtain permission directly from the copyright holder. To view a copy of this licence, visit http://creativecommons.org/licenses/by/4.0/.

\section{References}

1. Huber MT (2009) Energizing historical materialism: fossil fuels, space and the capitalist mode of production. Geoforum 40(1):105-115

2. IPCC (2014) Climate change 2014: synthesis report. IPCC, Geneva
3. Zhao P, Luo W, Han X (2019) Time-dependent and bi-objective vehicle routing problem with time windows. Adv Prod Eng Manag 14(2):201-212

4. Jin M, Granda-Marulanda NA, Down I (2014) The impact of carbon policies on supply chain design and logistics of a major retailer. J Clean Prod 85:453-461

5. Andersson FNG, Opper S, Khalid U (2018) Are capitalists green? Firm ownership and provincial CO2 emissions in China. Energy Policy 123:349-359

6. Lin J, Fridley D, Lu H et al (2018) Has coal use peaked in China: nearterm trends in China's coal consumption. Energy Policy 123:208-214

7. Li Q, Long R, Chen H (2017) Empirical study of the willingness of consumers to purchase low-carbon products by considering carbon labels: a case study. J Clean Prod 161:1237-1250

8. Liu Y, Yang D, Xu H (2017) Factors influencing consumer willingness to pay for low-carbon products: a simulation study in China. Bus Strateg Environ 26(7):972-984

9. Zhao R, Geng Y, Liu Y et al (2018) Consumers' perception, purchase intention, and willingness to pay for carbon-labeled products: a case study of Chengdu in China. J Clean Prod 171:1664-1671

10. Echeverría R, Moreira VH, Sepúlveda $\mathrm{C}$ et al (2014) Willingness to pay for carbon footprint on foods. British Food J 116(2):186-196

11. Wang X, Zhu Y, Sun $\mathrm{H}$ et al (2018) Production decisions of new and remanufactured products: implications for low carbon emission economy. J Clean Prod 171:1225-1243

12. Luo Z, Chen X, Wang X (2016) The role of co-opetition in low carbon manufacturing. Eur J Oper Res 253(2):392-403

13. Schultz K, Williamson P (2005) Gaining competitive advantage in a carbon-constrained world: strategies for European business. Eur Manag J 23(4):383-391

14. Gong D, Tang M, Liu S et al (2019) Achieving sustainable transport through resource scheduling: a case study for electric vehicle charging stations. Adv Prod Eng Manag 14(1):1

15. Benjaafar S, Li Y, Daskin M (2013) Carbon footprint and the management of supply chains: insights from simple models. IEEE Trans Autom Sci Eng 10(1):99-116

16. Tang M, Gong D, Liu S et al (2017) Finding key factors affecting the locations of electric vehicle charging stations: a simulation and ANOVA approach. Int J Simul Model (IJSIMM) 16(3):1

17. Giraud-Carrier FC (2014) Pollution regulation and production in imperfect markets. The University of Utah, Salt Lake City

18. Ma CS, Liu X, Zhang H et al (2016) A green production strategies for carbon-sensitive products with a carbon cap policy. Adv Prod Eng Manag 11(3):216-226

19. Ma CS, He H, Luo Z et al (2017) An inter-temporal production strategy under a carbon trading policy. Environ Eng Manag J (EEMJ) 16(10):2401-2412

20. Jian $\mathrm{M}, \mathrm{He} \mathrm{H}, \mathrm{MaC}$ et al (2019) Reducing greenhouse gas emissions: a duopoly market pricing competition and cooperation under the carbon emissions cap. Environ Sci Pollut Res 26:16847-16854

21. $\mathrm{He} \mathrm{H}, \mathrm{MaC}$ (2018) The production strategy for two products considering stochastic demand under cap-and-trade regulation. Int J Internet Manuf Serv 5(1):38-50

22. Pentico DW (1974) The assortment problem with probabilistic demands. Manage Sci 21(3):241-290

23. Parlar M (1988) Game theoretic analysis of the substitutable product inventory problem with random demands. Nav Res Logist (NRL) 35(3):397-409

24. Chand S, Ward JE, Weng ZK (1994) A parts selection model with one-way substitution. Eur J Oper Res 73(1):65-69

25. Bassok Y, Anupindi R, Akella R (1999) Single-period multiproduct inventory models with substitution. Oper Res 47(4):632-642

26. Pineyro P, Viera O (2010) The economic lot-sizing problem with remanufacturing and one-way substitution. Int $\mathrm{J}$ Prod Econ 124(2):482-488 
27. Piñeyro P, Viera O (2014) Note on "The economic lot-sizing problem with remanufacturing and one-way substitution.” Int J Prod Econ 156:167-168

28. Chen X, Chan CK, Lee Y (2016) Responsible production policies with substitution and carbon emissions trading. J Clean Prod 134:642-651

29. Thowsen GT (1975) A dynamic, nonstationary inventory problem for a price/quantity setting firm. Naval Res Logist Quart 22(3):461-476
30. Petruzzi NC, Dada M (1999) Pricing and the newsvendor problem: a review with extensions. Oper Res 47(2):183-194

'Publisher's Note Springer Nature remains neutral with regard to jurisdictional claims in published maps and institutional affiliations. 